\title{
Gibberellic acid and 6-benzyladenine reduce time to flowering and improve flower quality of Laelia anceps
}

\author{
Olga Tejeda-Sartorius*๑, Humberto Vaquera-Huerta ${ }^{\oplus}$, Libia Iris Trejo-Téllez ${ }^{\oplus}$, \\ Ramón Marcos Soto-Hernández ${ }^{\oplus}$, Julio Sánchez-Escudero ${ }^{\oplus}$
}

College of Postgraduates in Agricultural Sciences, Campus Montecillo, Carretera México-Texcoco km 36.5, Montecillo, Texcoco C.P. 56230, State of Mexico, Mexico

\begin{abstract}
The efficacy of plant growth regulators (PGRs) has been demonstrated in the flowering of economically significant orchid hybrids, but studies of their effects in wild species with commercial potential are scarce. The effect of three doses of gibberellic acid $\left(\mathrm{GA}_{3}\right)$ and 6-benzyladenine (BA), individually or in combination, and a control without PGRs, were evaluated during three flowering periods in Laelia anceps subsp. anceps, in the temporal behavior of flowering, morphofloral quality parameters and in potential residual effects and malformations. Significant effects were observed between the experimental periods and doses used, with a single application of PGRs in the first period reducing the days to visible flower induction (DVFI), days to anthesis (DAN) and days of flower life (DFL), mainly in the first period. There were no significant differences between doses for morpho-floral quality parameters within each period, but differences existed between experimental periods, where the life and size of the flower increased in the first period, and the number of flowers and flower stems increased significantly in the second period. The doses of $2.37 \mathrm{mg} \cdot \mathrm{L}^{-1} \mathrm{BA}+100 \mathrm{mg} \cdot \mathrm{L}^{-1} \mathrm{GA}_{3}$ showed highest significant consistency in the reduction of DVFI, DAN and increase of DFL and flower stems in the study. There were no floral malformations, and a positive residual effect was observed in temporal variables in the second period. Most of the doses used encourage beneficial effects in the various aspects of flowering evaluated.
\end{abstract}

Keywords: BA, GA, Orchidaceae, orchids, plant growth regulators, seasonal behavior, survival analysis

\section{Abbreviations:}

BA, 6-benzyladenine; d, Days; DAN, days to anthesis; DVFI, days to visible flower induction; DFL, days of flower life; FSL, flower stem length; GA 3 , gibberellic acid; NFR, number of flowers per raceme; NFS, number of flower stems; PGRs, plant growth regulators; PVFI, percentage of visible flower induction; SF/LENGTH, size of flower/length; SF/WIDTH, size of flower/width; VFI, visible flower induction.

\section{INTRODUCTION}

Orchidaceae is the second largest family of angiosperms with 20,000 to 30,000 species, with beautiful, fascinating, and intricate blooms (Hágsater et al., 2005). This family is constantly under the burden of collection for trade, which ranks it as one of the most vulnerable to extinction in nature. Significant gaps in understanding its induction processes and floral development, coupled with slow growth and long life cycles, represent a major challenge in overcoming the risk of extinction as a result of existing improvement mechanisms and protocols (Wang et al., 2017).

Current market demands tend to prolong the growing seasons and off-season development of various species,

*Corresponding author.

e-mail: olgats@colpos.mx (Olga Tejeda-Sartorius). 
primarily ornamental plants (Bernier et al., 1993; Ha, 2014). Many studies converge on the awareness that plants initiate flowering in response to environmental signals and endogenous pathways (Amasino and Michaels, 2010), and characteristic cells are relayed and/ or modulated by different hormones. Recent hormonal studies outline a more specific role of certain hormones in the floral transition and describe their modes of interaction with established floral pathways (Conti, 2017).

Plant growth regulators (PGRs, also known as bioregulators) are classified as natural or synthetic compounds that affect, as desired, the development or metabolic processes in higher plants. They are not phytotoxic, do not serve as plant nutrients and are typically administered at low doses (Rademacher, 2018). For decades, the use of PGRs has attracted attention in agriculture and horticulture (Nickell, 1994) and has also been used in orchid growth and development, especially in floral initiation and development (Hew and Clifford, 1993). Bernier et al. (1993) reported that cytokinins are part of the various physiological signals that induce flowering and floral development (Wang et al., 2019). The use of exogenous cytokinins in plants induces or promotes early flowering in several orchid species or enhances aspects of floral development (Blanchard and Runkle, 2008; Wu and Chang, 2009; Wu and Chang, 2012). Gibberellins (GAs) are responsible for regulating a variety of plant development processes, including major flowering stages (Kozłowska et al., 2007). The exogenous effect of GAs on plant flowering is difficult to determine because this effect may act differently in different species (Levy and Dean, 1998; Richards et al., 2001). In some cases, its application may be ineffective in inducing flowering, but in long-day plants, gibberellic acid $\left(\mathrm{GA}_{3}\right)$ may have different effects, depending on the species (Kozłowska et al., 2007). Thus, some reports show that $\mathrm{GA}_{3}$ is associated with the induction of flowering in several orchid species: Miltoniopsis (Matsumoto, 2006), Brassocattleya (Cardoso et al., 2010) and Phalaenopsis (Cardoso et al., 2012).

Most studies report the effect of PGRs on orchid flowering for an experimental cycle, several of which have been shown to be successful, but there is insufficient knowledge of potential malformations in the flowers, as noted by Richards et al. (2001) and Emongor (2007) for Arabidopsis, and Wu and Chang (2009) for Phalaenopsis. Additionally, it is important to assess possible residual effects, as reported for other crops with paclobutrazole (PBZ), such as in fruit trees, Citrus volkameriana (Hadlow and Allan, 1989) and mango (Kishore et al., 2015). For orchids of sympodial growth, it is therefore important to analyze the quality of flowering and the subsequent effect of PGRs on the development of new vegetative shoots, as they focus on the success of the next flowering. Thus, it is necessary to generate information on the viability of applications of PGRs on orchids and their subsequent behaviour, as suggested by Hew and Lee (1989) and Sajjad et al. (2017) for ornamentals in general.
Based on the above, the effect of different exogenous doses of PGRs, 6-benzyladenine and $\mathrm{GA}_{3}$, individually or in combination, was evaluated during three flowering periods for the Laelia anceps subsp. anceps orchid, in: (i) the temporal behavior of flowering, (ii) morpho-floral quality parameters and (iii) potential residual effects or malformations in the flowering.

\section{MATERIALS AND METHODS}

\section{Plant material}

Adult plants of $L$. anceps subsp. anceps (abbreviated as L. anceps subsequently) were divided and transplanted with 4-6 pseudobulbs into $1 \mathrm{~L}$ capacity containers with a mixture of substrate medium in the following ratio; pine bark $\left(\right.$ Ecorteza $\left.^{\circledR}\right)$ : peat moss $\left(\right.$ Kekkilä $\left.^{\circledR}\right)$ : perlite (60:20:20, v:v:v). The plants were kept for one year in adaptation, with fertilizer application using Peters $^{\circledR}$ 30-10-10 $\left(1 \mathrm{~g} \cdot \mathrm{L}^{-1}\right)$ during the vegetative phase and Peters $^{\circledR} 10-30-20\left(1 \mathrm{~g} \cdot \mathrm{L}^{-1}\right)$ during the period considered inductive. The following year, 2017, the plants were assigned to different treatments, as described below. The study was carried out after taking into account three experimental periods: period 1 (2017), period 2 (2018) and period 3 (2019).

\section{Experimental period 1}

\section{Vegetative growth phase}

At the beginning of the experimental phase, the plants were selected with new vegetative shoots between $3 \mathrm{~cm}$ and $5 \mathrm{~cm}$. Applications with Peters ${ }^{\circledR} 30-10-10\left(1 \mathrm{~g} \cdot \mathrm{L}^{-1}\right)$ were started on all plants during this time, beginning from March 17th, with applications every 7 days until April 21st.

\section{Inductive phase}

The application of PGRs is considered as the beginning of the floral inductive phase (treatments), in which the new shoots were between $5 \mathrm{~cm}$ and $10 \mathrm{~cm}$ long, measured from the base of pseudobulb to leaf tip, with differentiated leaf and pseudobulbs, but the leaf blade was unopened. In this phase, all plants including those of the control, received a nutrient solution with the following composition in $\mathrm{mg} \cdot \mathrm{L}^{-1}: \mathrm{N}, 100 ; \mathrm{P}, 200 ; \mathrm{K}$, 200; Ca, 100; Mg, 50; S, 56; Fe, 5.00; Cu, 0.19; Zn, 0.47; Mn, 2.33; B, 0.43; and Mo, 0.17.

\section{Treatments and experimental design}

Solutions were prepared with different doses of PGRs: gibberellic acid $\left(\mathrm{GA}_{3}\right.$; Gibiotin ${ }^{\circledR}$ BiochemSystems SA de CV, Mexico), and 6-benzyladenine (6BA; [alternatively, BA]; 6-benzyladinine [N- (phenylmethyl) -1H-purine6amine; CyStar ${ }^{\circledR}$ Valent de México S. A. de C. V.). With concentrations $\left(\mathrm{mg} \cdot \mathrm{L}^{-1}\right)$ : BA: 9.5, 19, 28.5; GA: 400, 600, 800; $\mathrm{BA}+\mathrm{GA}_{3}: 2.37+100 ; 4.75+150$; $7.12+200$; and a control without PGRs. 
The solutions were prepared using distilled water, and prior to adding the doses of PGRs, $1 \mathrm{~mL} \cdot \mathrm{L}^{-1}$ of Kinetic $^{\circledR}$ (Valent de México S. A. de C. V.) was added as an adjuvant for foliar application. The solutions were adjusted to a $\mathrm{pH}$ of 5.5. The plants were sprayed with the PGRs solutions in spraying amounts of $30-40 \mathrm{~mL}$ per plant in the evening, from 17:00 h to $18: 00 \mathrm{~h}$, with temperatures inside the greenhouse ranging from $20^{\circ} \mathrm{C}$ to $25^{\circ} \mathrm{C}$, respectively. Control plants were sprayed with only distilled water. PGRs were applied four times every 7 days, from May 12th to June 1st.

\section{Experimental periods 2 and 3}

To observe the subsequent effect of the PGRs, the plant material of period 1 was evaluated in 2018 and 2019 (Experimental periods 2 and 3). In these periods, the steps of period 1 were adopted: Vegetative growth phase (applications with Peters ${ }^{\circledR} 30-10-10 ; 1 \mathrm{~g} \cdot \mathrm{L}^{-1}$ ) and Floral inductive phase (with the nutrient solution indicated previously). Nutrient applications were made considering the same sizes of the vegetative shoots of period 1; however, in periods 2 and 3, the doses of PGRs were not applied. The criterion for setting the visible flower induction (VFI) dates was when $15 \%$ of flower budding occurred (April 1st), since they began earlier than in 2017. The plants were distributed in a split-plot design, where time was considered the largest plot, while each PGR dose was considered the smallest plot, with eight randomized repetitions. A container with one plant was considered as the experimental unit.

\section{Climate data}

Environmental data was collected with a $\mathrm{HOBO}^{\circledR}$ Data Logger Onset, placed $20 \mathrm{~cm}$ above the aerial part of the plants during the experimental period, and the reading recorded every $5 \mathrm{~min}$. The data were downloaded using the HOBOware PRO software. For data presentation, these were separated considering day-time data, from 7:00 h to 18:59 h, and night-time data, from 19:00 h to 6:59 h. Day and night averages were obtained, and those for each day were in turn averaged per month (Figure 1).

\section{Variables of study}

The following data were collected: (i) days to visible flower induction (DVFI): when the inflorescence reached an approximate size of $10 \mathrm{~cm}$ above the apex of the pseudobulb, after the application of treatments with PGRs; (ii) percentage of visible flower induction (PVFI): based on the number of repetitions per treatment; (iii) days to anthesis (DAN): considered from the FI record until the anthesis of the first flower of the raceme; (iv) days of flower life (DFL): from anthesis to senescence of the first flower of the raceme; (v) number of flower stems (NFS): in addition to the current shoot to start the application of PGRs, the number of new vegetative shoots was counted from the application of the treatments and, consequently, the NFS, which was the same as the number of vegetative shoots, since these culminated in floral stem; (vi) number of flowers per raceme (NFR): the number of flower buds in the raceme was counted; (vii) flower size: the length (FS/length) was considered in flower size, from sepal to sepal; and the width (FS/width), from petal to petal; (viii) flower stem length (FSL): once in a state of anthesis, the floral stem was measured from the apex of the pseudobulb to the beginning of the raceme. All the variables were recorded in situ, until the date of the senescence of the first flower of the raceme in each plant.

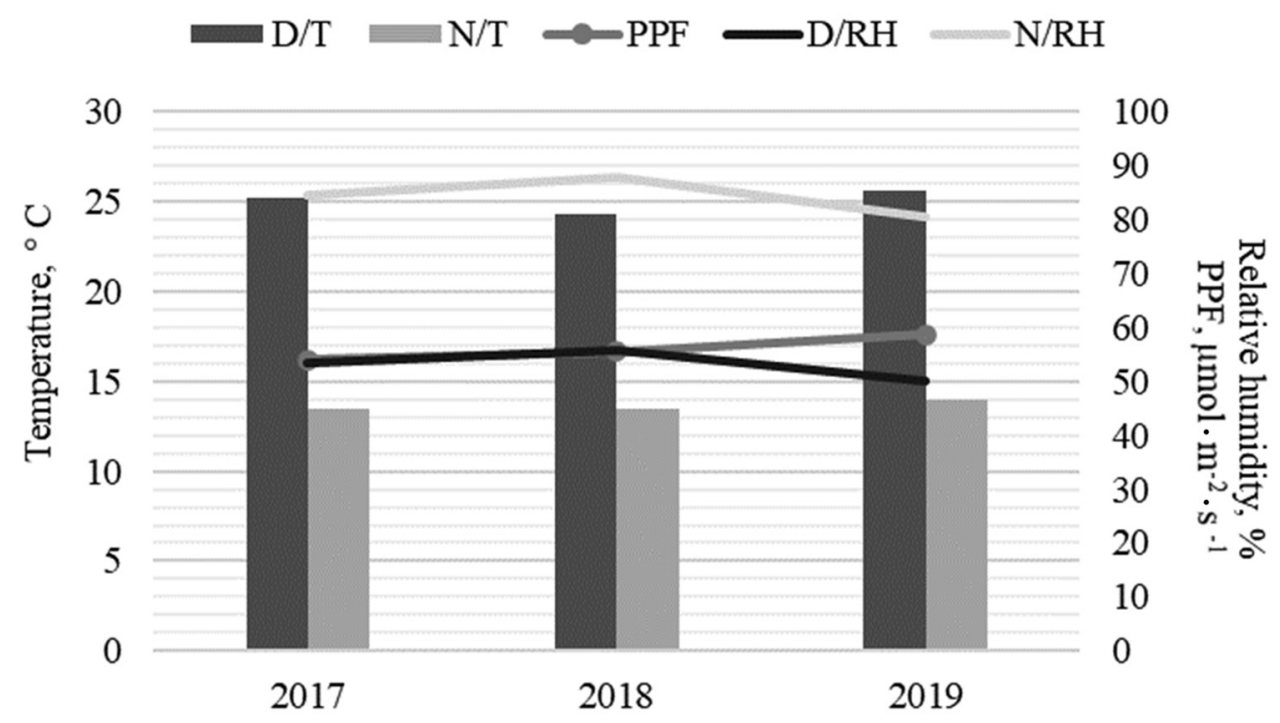

Experimental period

Figure 1. Average $\mathrm{D} / \mathrm{T}$ and $\mathrm{N} / \mathrm{T} ;{ }^{\circ} \mathrm{C}$, percentage of $\mathrm{D} / \mathrm{RH}$ and $\mathrm{N} / \mathrm{RH}$, and $\mathrm{PPF} ; \mu \mathrm{mol} \cdot \mathrm{m}^{-2} \cdot \mathrm{s}^{-1}$, by experimental period (2017 to 2019). D/T, day-time temperature; D/RH, day-time relative humidity; N/T, nights temperatures; N/RH, night relative humidity; PPF, photosynthetic photon flux. 


\section{Statistical analysis}

Survival analysis is a statistical procedure used primarily for clinical analysis and is currently also used in livestock and agricultural research (mostly in epidemiological studies) (Kleinbaum and Klein, 2005; Załuski et al., 2018). However, survival analysis is rarely used in ornamentals, and at present there is no knowledge of its use in orchid studies, but it was considered interesting to apply it in the present investigation due to the long flowering period of $L$. anceps.

The temporal events of study were DVFI, DAN and DFL. The survival analysis was considered from the beginning of the applications of the treatments with PGRs: May 12th in 2017, and then up to April 1st for the analysis of the 2018 and 2019 periods. The analysis of each period is concluded at the end of the corresponding observations. The observations for each variable were censored as follows: for DVFI, at 60 days after the start of the application of treatments; for DAN, at 120 days after flower induction; and for DFL, at 10 days after anthesis. The Kaplan-Meier estimator and the Log-Rank test were used to investigate the impact of treatments and experimental periods on the variables DVFI, DAN and DFL in the LIFETEST procedure of the SAS/STAT 9.4 (SAS, Institute Inc. Cary, N.C., USA). Weibull regression was also used, by deploying the LIFEREG procedure of SAS 9.4, which is another way of modelling the relationship between the variables DVFI, DAN and DFL as a function of treatments and time periods.

To explain the effect of PGRs over time on plant response variables (DFL, NFS, NFR, SF/length, SF/ width and FSL), a repeated measure analysis was used by applying the GLM procedures and the mixed model MIXED from SAS/STAT 9.4. To study the comparison of means, the Tukey test (0.05) was used with the SAS PLM procedure. In addition, to compare the chemical treatments, a two-way ANOVA was done to see the effect of chemicals on flowering.

\section{RESULTS}

In 2017, with the different doses of BA, the PVFI ranged from $50 \%$ to $75 \%$, but in 2018 and 2019 it reached $100 \%$. In general, the doses of $\mathrm{GA}_{3}$ and the combination of $\mathrm{BA}+\mathrm{GA}_{3}$ raised the percentages between $75 \%$ and $100 \%$ in the same manner during the three experimental periods, and the control behaviour was similar. Furthermore, $\mathrm{GA}_{3}$ and its combination with BA presented some abortions of flower buds. In particular, the $400 \mathrm{GA}_{3}$ dose presented the lowest percentage of FI during the three periods (Figure 2).

\section{Days to visible flower induction}

The temporal effect of the PGRs was significant only between periods for DVFI (log-rank test and Wilcoxon test, $p<0.0001$ ). 2017 (year of application of the PGRs) has the shortest period, with an average of 37 days, being 6 days and 17 days shorter, respectively, than in 2018 and 2019. Figure 3 shows the mean residual lifetime for DVFI for 2017, 2018 and 2019 to be 72, 70 and 114, respectively. The Weibull regression analysis agrees with the log-rank test since it showed statistical differences only for the evaluation between periods $(p<0.0001)$. Although there were no significant differences with the doses used, it is worth mentioning that in 2017 there were doses that decreased the DVFI in relation to the control: the intermediate dose of BA for 8 days, and the three doses of $\mathrm{BA}+\mathrm{GA}_{3}$ were less than the control in an average of 10 days; even the low dose of $\mathrm{BA}+\mathrm{GA}_{3}$ decreased in an average of 14 days. In 2018, all treatments with PGRs decreased by an average of 15 days in relation to the control (data not shown).

\section{Days to anthesis}

Significant differences were observed for DAN between periods (log-rank test and Wilcoxon test: $p<0.0001$ and $p=0.0004$, respectively) (Figure 4A). As for DVFI, the mean time for DAN was lower in 2017 (115 days)

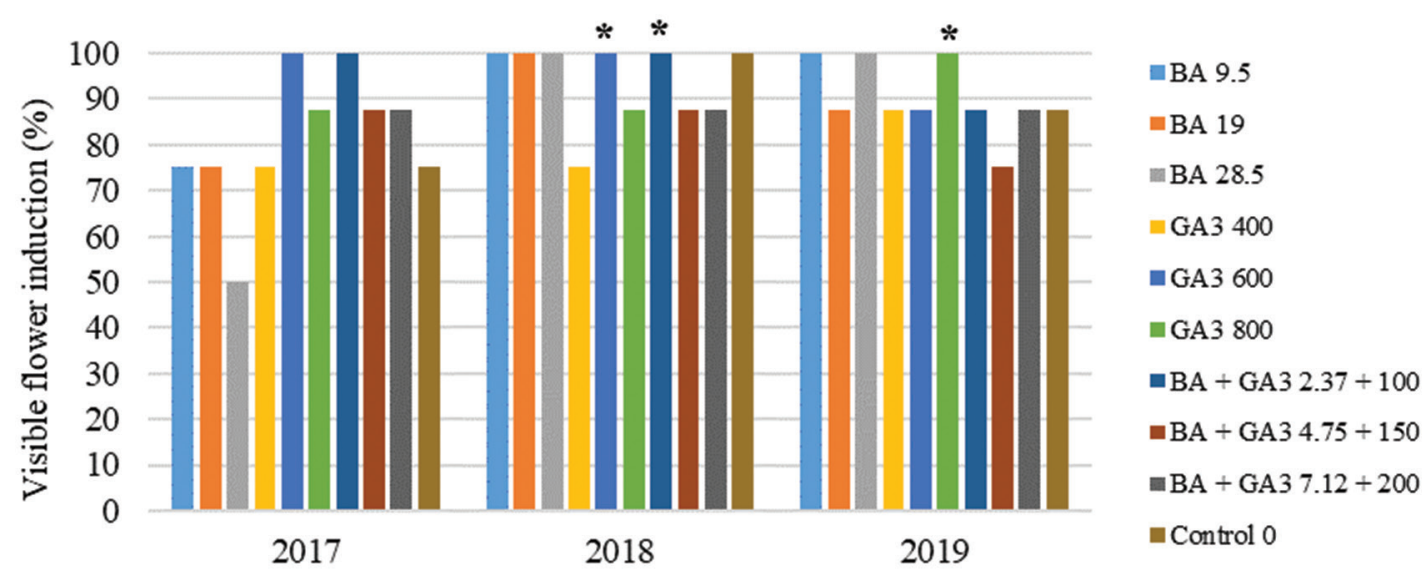

Periods

Figure 2. Percentage of visible floral induction of $L$. anceps in three experimental periods, by effect of different doses of BA and $\mathrm{GA}_{3}$. BA, 6-benzyladenine; $\mathrm{GA}_{3}$, gibberellic acid. *Indicates an abortion in treatment. 


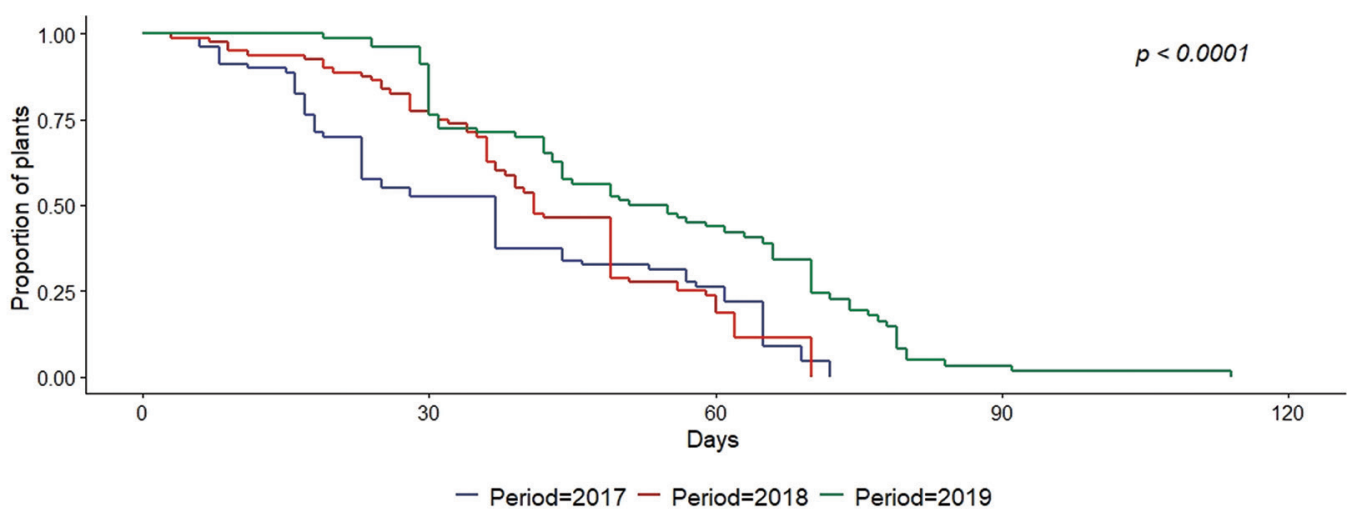

Figure 3. Survival curves represent the proportion of $L$. anceps plants induced to flowering per day, with the effect of different doses of PGRs: $\mathrm{GA}_{3}$ and BA, in three experimental periods. Differences in the survival curves are significant with the log-rank test $(p \leq 0.05)$. BA, 6-benzyladenine; GA , gibberellic acid; PGRs, plant growth regulators.
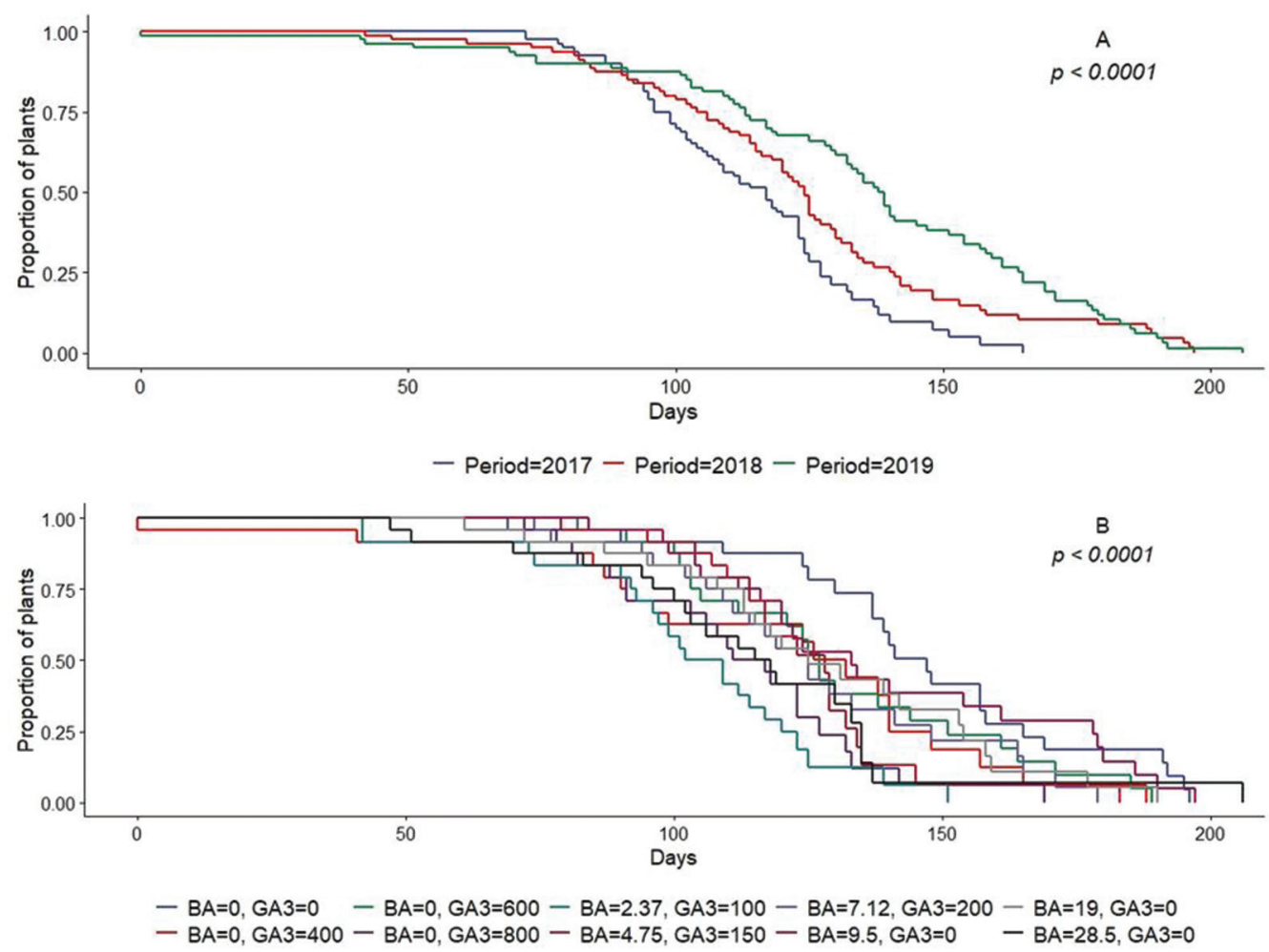

Figure 4. Survival curves represent the proportion of $L$. anceps plants that reached anthesis per day, in each experimental period (A), and by effect of treatments in the global analysis period (B), with the application of different doses of PGRs: $\mathrm{GA}_{3}$ and BA. Differences in the survival curves are significant with the log-rank test $(p \leq 0.05)$. BA, 6-benzyladenine; $\mathrm{GA}_{3}$, gibberellic acid; PGRs, plant growth regulators.

for 9 days and 20 days compared to 2018 and 2019. The anthesis period in 2017, 2018 and 2019 lasted until 165 days, 197 days and 206 days, respectively, that is, an approximate difference of 41 days between the beginning and the end of the study (Figure 4A).

Further, there were significant differences between treatments in the analysis of the global period (2017-2019) (log-rank test and Wilcoxon test: $p<0.0001$ and $p=0.0002$, respectively) (Figure 4B), in which the dose 2.37 BA + 100 $\mathrm{GA}_{3}$ presented faster anthesis with an average period of
104 days that ended on day 151 (Figure 4B), compared to the average 147 days of the control that ended on day 196. The remaining tests doses of PGRs also caused decreased DAN, with average values of 113-139 days. Average DAN for treatment with $28.5 \mathrm{BA}$ doses was 116 days, while the probability of survival at day 206 was extended, even exceeding 10 days to the control treatment (Figure 4B).

In the experimental period analysis, for 2017, significant differences were observed between treatments for DAN (log-rank test and Wilcoxon test: 
$p<0.0036$ and $p=0.0487$, respectively) (Figure 5A). The PGRs promoted anthesis to occur earlier (109 days, average of PGRs treatments) than in the control group (144 days), where the dose of $400 \mathrm{GA}_{3}$ decreased the anthesis by 52 days compared to the control. Survival curves showed that the anthesis period for most PGR treatments was between day 120 and 133, except for 600 $\mathrm{GA}_{3}$ dose, which was extended to 151 days. Specifically, doses of $9.5 \mathrm{BA}$ and $19 \mathrm{BA}, 400 \mathrm{GA}_{3}$, as well as 2.37 $\mathrm{BA}+100 \mathrm{GA}_{3}$ and $4.75 \mathrm{BA}+150 \mathrm{GA}_{3}$, completed the full anthesis period in the shortest time (120-124 days), with an average residual difference of 44 days more in the control (Figure 5A).

Most doses of PGRs extend their DAN by 11 days and 22 days in 2018 and 2019 compared to 2017. The control was more constant over the three periods (from 144-149 days). Statistical differences between treatments were observed in 2018 (test log-rank and test Wilcoxon: $p<0.0033$ and $p=0.0095$, respectively). The dose $2.37 \mathrm{BA}+100 \mathrm{GA}_{3}$ represents the shortest average time to anthesis (96.4 days) vs. 147.8 days of the control. Similarly, this same dose showed constancy by reducing its full time to anthesis (day 125), that is, 71 days less than the control. The effect of doses 28.5 BA and 4.75 $\mathrm{BA}+150 \mathrm{GA}_{3}$, which showed a total survival time of 130 days and 135 days, was also outstanding in relation to the control that extended its DAN period to day 196 (Figure 5B). Dose $400 \mathrm{GA}_{3}$ significantly extended their duration to anthesis (188 days) in 2018 compared to the opposite effect in 2017 (Figure 5B).

The year 2019 (Figure 5C) showed a more dispersed behaviour of treatments, and there were no statistical differences in the log-rank test $(p=0.0729)$; however, the Wilcoxon test presented differences $(p=0.0244)$.
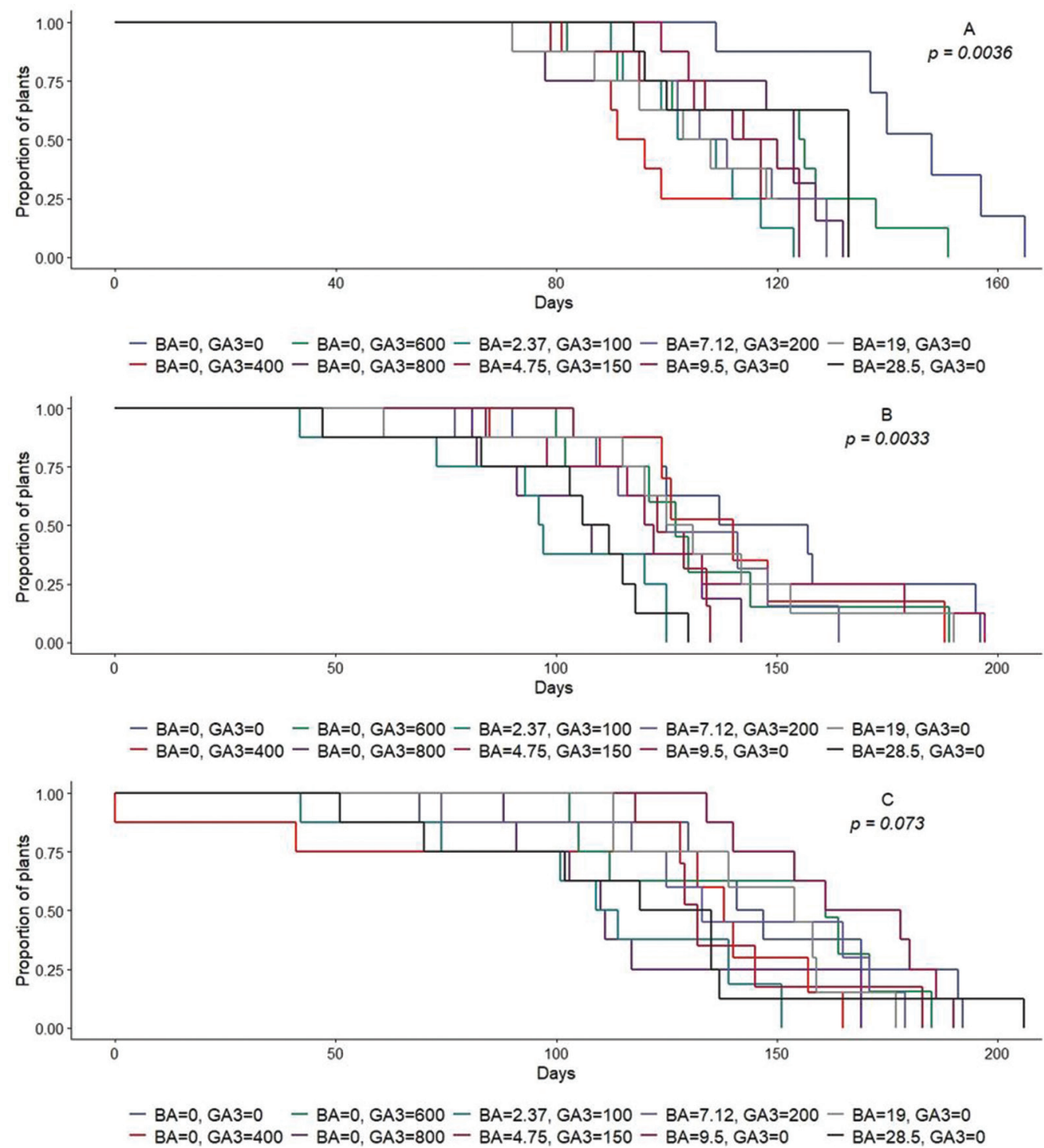

Figure 5. Survival curves represent the proportion of $L$. anceps plants that reached anthesis daily, in each experimental period: 2017 (A), 2018 (B) and 2019 (C), by the effect of different doses of PGRs: GA and BA. Differences in the

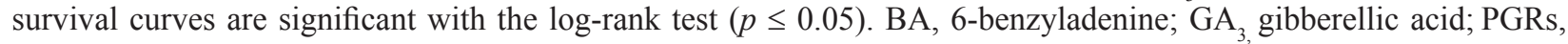
plant growth regulators. 
Consistently, the dose $2.37 \mathrm{BA}+100 \mathrm{GA}_{3}$ presented the lowest average in DAN (109 days), 38 days less than the control, followed by the doses in $28.5 \mathrm{BA}, 400$ $\mathrm{GA}_{3}$ and $800 \mathrm{GA}_{3}$ (119 days, 115 days and 120 days, respectively). The remaining doses presented an average between 140 DAN and 165 DAN. The same dose 2.37 $\mathrm{BA}+100 \mathrm{GA}_{3}$ completed its anthesis period in the shortest time (151 days) compared to 192 days where the control was prolonged (Figure 5C). For DAN, as for the survival analyses, the Weibull regression generated statistical differences between periods $(p<0.0001)$, between treatments per global period $(p<0.0001)$ and treatments per experimental period $(p=0.0287)$.

\section{Days of flower life}

On the one hand, there were significant differences between the experimental periods and the period from the day of the anthesis to the senescence of the same flower (test log-rank and test Wilcoxon: $p=0.0318$ and $p=0.0009$ ) (Figure 6A). The flower lifetime distribution curve for 2017 was observed further away (right side) from the beginning and throughout the duration of the survival cycle, although at the end, the residual times for each period were similar and ended between day 36 and 40 (Figure 6A). On the other hand, statistical differences between treatments were presented for the 2017 period (log-rank test and Wilcoxon test: $p<0.0001$ and $p<0.0001$ ) (Figure 6B), where the doses that provided more DFL were the high doses of BA, 28.5, and intermediate doses of BA (4.75) + GA (150), with 28 days. In general, the PGRs doses promoted more DFL between 25.4 days and 27.7 days compared to 18.3 days of the control, except for $9.5 \mathrm{BA}, 600 \mathrm{GA}_{3}$ and $800 \mathrm{GA}_{3}$ that presented average DFL values between 21.5 days and 23.7 days.

Most of the doses, excluding $600 \mathrm{GA}_{3}$ and 7.12 $\mathrm{BA}+200 \mathrm{GA}_{3}$, showed plants with sustained DFL from day 10 and concluded their residual survival periods between 31 days and 35 days; this is even more than $2.37 \mathrm{BA}+100 \mathrm{GA}_{3}$ indicating a more concentrated flower life: from day 23 to day 40 (Figure 6B). There were no statistical variations between DFL treatments in 2018 and 2019, but it was observed that plants with certain doses appeared to extend their residual survival between days 30 and 36, while the control treatment curve indicated that their average lifespan was closer to day 20 (data not shown). For DFL, the Weibull regression showed significant differences only for treatments per period $(p=0.0192)$.

\section{Flower development}

The statistical analysis with the repeated measures model (MIXED) showed significant differences for floral development parameters between experimental periods (Table 1), but there were no significant differences between treatments within each period (data not shown). Thus, for the flower life, as with the log-rank test, significant differences $(p=0.0005)$ were observed,

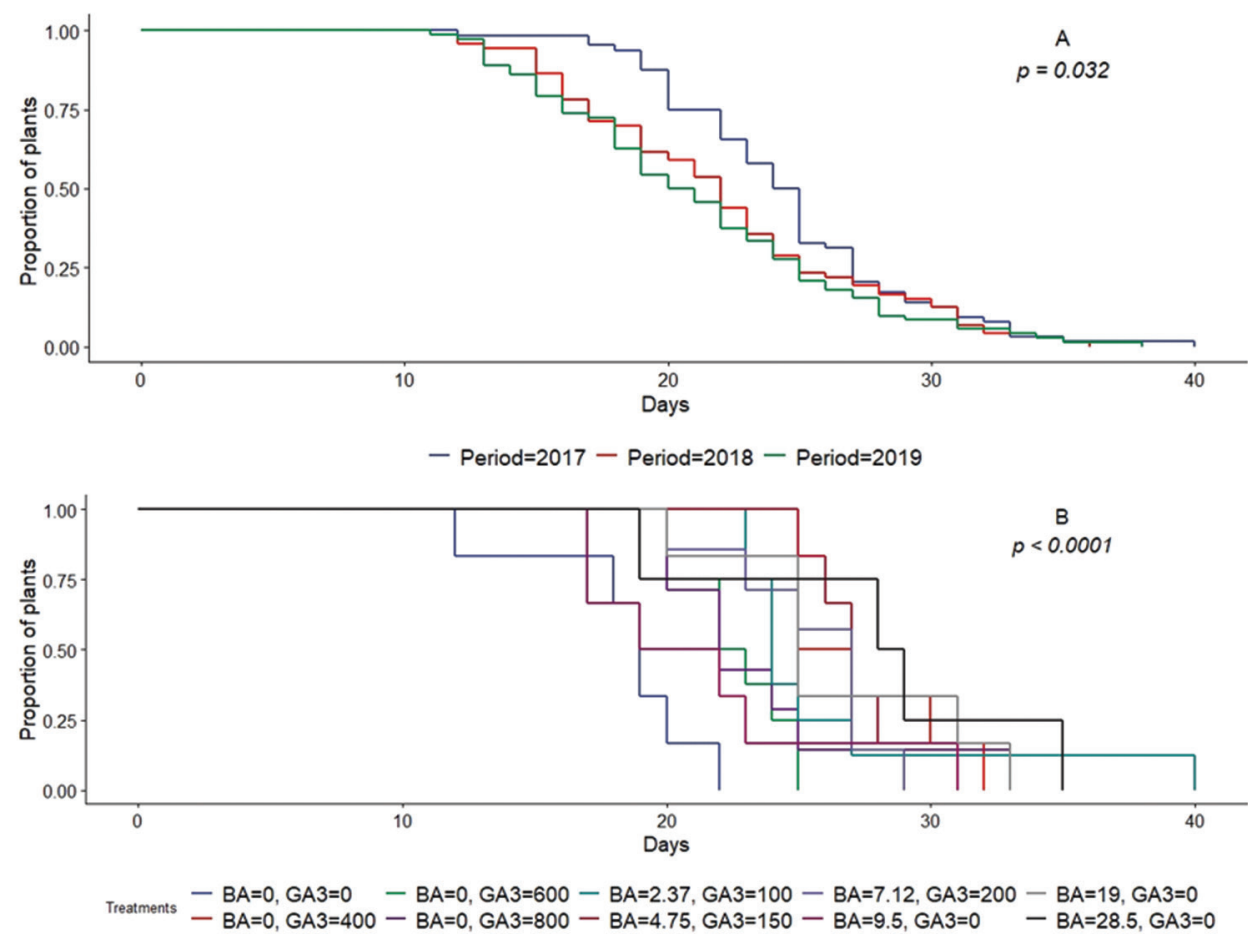

Figure 6. Survival curves represent the proportion of $L$. anceps plants with live flowers per day, in each experimental period (A), and by effect of treatments in the period 2017 (B), with the application of different doses of PGRs: GA 3 and BA. Differences in the survival curves are significant with the log-rank test $(p \leq 0.05)$. BA, 6-benzyladenine; GA, gibberellic acid; PGRs, plant growth regulators. 
as well as for its size (length $\times$ width; $p=0.0275$ and $p=0.0004$ ), which were higher in 2017 compared to 2018 and 2019. The NFS was higher in $2018(p<0.0001)$ compared to the other periods (Table 1).

According to MIXED, some of the doses with PGRs generated statistical differences in floral development variables, between the first experimental period (2017) and subsequent periods (Table 2). The single, intermediate and high doses of BA, 19 and 28.5, promoted the highest NFS $(p=0.0233$ and $p=0.0204)$ in 2018 which remained constant in 2019, compared to 2017. Similar doses, except 19 BA for flower length, had an opposite effect, as they promoted significantly greater growth, in terms of length $(p=0.0114)$ and flower width (19 BA, $p=0.0030 ; 28.5 \mathrm{BA}, p=0.0524)$ in 2017 , compared to the other experimental periods (Table 2).

The MIXED detected that the $400 \mathrm{GA}_{3}$ dose significantly increased the flower life in 2017 $(p=0.0257)$ and decreased it in 2019 by 7.3 days, while the $800 \mathrm{GA}_{3}$ dose increased in 2018 by 6 days $(p=0.0443)$ compared to 2019. The $600 \mathrm{GA}_{3}$ significantly increased the NFS $(p=0.0004)$ in 2018 compared to 2017 and 2019. On the other hand, SF/ LENGTH was statistically higher $(p=0.0257)$ in 2019 with the dose of $800 \mathrm{GA}_{3}$ (Table 2).

The combination $2.37 \mathrm{BA}+100 \mathrm{GA}_{3}$ significantly increased $(p=0.0443)$ the flower life in 2017 compared to 2018 and 2019 by 7.1 days and 7.9 days. This same dose and $4.75 \mathrm{BA}+150 \mathrm{GA}_{3}$ increased the NFS in 2018 ( $p=0.0055 ; p=0.0190)$ compared to the other two periods and promoted greater flower width $(p=0.0278)$ in 2017 compared to 2018 (Table 2); however, the dose $7.12 \mathrm{BA}+200 \mathrm{GA}_{3}$ significantly increased $(p=0.0068)$ the NFR in 2018 (2.57) compared to 2017 (1.57) and 2019 (1.86). There were no statistical differences for FSL (data not showed).

The two-way ANOVA analysis showed statistical differences for flower life in 2017 (BA, $p=0.0019$; $\left.\mathrm{GA}_{3}, p=0.0188\right)$. In addition, there were significant differences for length of flower in 2017 (BA, $p=0.0026$, $\left.\mathrm{GA}_{3}, p=0.0255\right) ; 2018\left(\mathrm{GA}_{3}, p=0.0233\right)$; and in 2019 $\left(\mathrm{GA}_{3}, p=0.0337\right)$. Further, for width of flower, only in 2017 did the analysis show a statistical difference with BA $(p=0.0268) . \mathrm{GA}_{3}$ also showed significant differences in $2018(p=0.0386)$.

\section{DISCUSSION}

\section{Time to flower induction}

The PGRs used, including $\mathrm{BA}$ and $\mathrm{GA}_{3}$, have an influence on the reduction of time to floral induction of L. anceps. The full DVFI period ended 43 days earlier in 2017 and 2018 compared to 2019 (Figure 3). Even in the year of application of the PGRs, an average reduction of DVFI was observed on 6 days and 17 days compared to 2018 and 2019, respectively. Thus, we observe that there is a more concentrated period from induction to flowering in 2017 and 2018. Although no significant difference was found with the doses used, the reduction of DVFI for 14 days with low dose of BA + GA in 2017 is a considerable time. In a three-year study, Hew and Lee (1989) reported that they managed to change the peak of flower production of $\times$ Aranda Christine cv. ' 130 ' for two weeks, when removing buds, which is one of the suggested treatments to control the induction of flowering in orchids, in addition to chemical control, such as PGRs (Hew and Yong, 2004). Similar to our data, Blanchard and Runkle (2008) reported the effect of BA and its combination with GAs, as well as different times of BA application and temperature management for Phalaenopsis Brother Apollo '072', and reported significant differences in reducing the time to visible inflorescence in plants treated with the different growth regulators from 2 days to 6 days compared to the control (14-18 days with regulators vs. 20 days of the control); for $P$. Golden Treasure ' 470 ', from 13 days to 17 days with regulators vs. 22 days of the control; in Doritaenopsis 'Alice Girl', Doritaenopsis 'Malibu Chablis' and Phalaenopsis 'Pink Twilight', BA treatments resulted in reduction of time from 4 days to 7 days, 4 days to 12 days and 2 days, respectively, compared to the control. Matsumoto (2006) reported that $\mathrm{GA}_{3}$ doses of $2.5 \mathrm{mM}$ and $5 \mathrm{mM}$ significantly reduced the emergence time of the inflorescence of Miltoniopsis Bert Field 'Eileen' by 10.9 days and 7 days below the 114.9 days of the control. Also, a similar reduction trend was observed in $M$. Rouge 'Akatsuka' by 48.7 days and 20.9 days below the 183 days of the control. In general, the effect of PGRs is more noticeable in promoting earlier flowering in wildtype plants, such as the case of $L$. anceps in our study,

Table 1. Means of the effect of different doses of 6-benzyladenine and gibberellic acid on morpho-floral quality parameters of $L$. anceps, by experimental period.

\begin{tabular}{lcccccc}
\hline Experimental period & FL & NFS & NFR & SF/length & SF/width & FSL \\
\hline 2017 & $24.55 \mathrm{a}$ & $1.44 \mathrm{c}$ & $2.09 \mathrm{a}$ & $9.36 \mathrm{a}$ & $7.81 \mathrm{a}$ & $38.90 \mathrm{a}$ \\
2018 & $22.01 \mathrm{~b}$ & $2.22 \mathrm{a}$ & $2.35 \mathrm{a}$ & $9.07 \mathrm{ab}$ & $7.20 \mathrm{~b}$ & $35.45 \mathrm{a}$ \\
2019 & $21.01 \mathrm{~b}$ & $1.77 \mathrm{~b}$ & $2.15 \mathrm{a}$ & $8.80 \mathrm{~b}$ & $7.11 \mathrm{~b}$ & $35.71 \mathrm{a}$ \\
\hline
\end{tabular}

Columns with different letters indicate statistical differences (Tukey, $p \leq 0.05$ ).

FL, flower life; FSL, flower stem length; NFR, number of flowers per raceme; NFS, number of flowers stem; SF/LENGTH, size of flower/ length; SF/WIDTH, size of flower/width. 
(

(1)

to

to

a
since the reduction periods are much greater, compared
to those reported for some orchid hybrids.

\section{Time to anthesis}

In analyzing the experimental periods, the average time to reach anthesis in 2017 was shorter by 9 days and 20 days, compared to 2018 and 2019, and the survival period in 2017 extended to day 165, which was 32 days and 41 days shorter when compared to 2018 and 2019 (Figure 4A). In 2017, the single dose $400 \mathrm{GA}_{3}$ generated the shortest time to anthesis (92 days). This finding is important because some studies suggest that GAs may have a negligible amount of impact on flowering and that it takes a combination of some cytokinin to produce some effect (Hew and Yong, 2004). Phengphachanh et al. (2012) reported that Rhynchostylis gigantea (Lindl.) Ridl., under the effect of natural conditions of the day (NC) and short day (SD), with application of $\mathrm{GA}_{3}$ at concentrations of $0 \mathrm{ppm}$ and $3000 \mathrm{ppm}$, reduced endogenous levels of ABA and increased $\mathrm{t}$-ZR in leaf and stem, which may be related to the initiation of flower buds and early flowering, under both photoperiod conditions, but mainly under SD. With similar data, Cardoso et al. (2012) tested doses of $0 \mathrm{mg} \cdot \mathrm{L}^{-1}, 125 \mathrm{mg} \cdot \mathrm{L}^{-1}, 250 \mathrm{mg} \cdot \mathrm{L}^{-1}, 500 \mathrm{mg} \cdot \mathrm{L}^{-1}$ and $1,000 \mathrm{mg} \cdot \mathrm{L}^{-1} \mathrm{GA}_{3}$ in the vegetative and reproductive development of Phalaenopsis FSNT 'Dai-Itigo'. They observed that with the $125 \mathrm{GA}_{3}$ dosage, $50 \%$ of plants bloomed 6-12 months earlier than plants not treated with $\mathrm{GA}_{3}$. Similarly, Matsumoto (2006) used $2.5 \mathrm{mM}$ or $5 \mathrm{mM} \mathrm{GA}_{3}$ dosage, N6-Benzyladenine (BA; $25 \mathrm{mM}$ or $50 \mathrm{mM}$ ), alone or in combination, in Miltoniopsis orchids. Plants treated with both individual doses of $\mathrm{GA}_{3}$ decreased their inflorescence initiation time by 10 days and to 49 days for M. Eillen and 'Akatsuka,' respectively.

In addition, in our research, the individual doses of BA showed their best performance in 2017 in reducing DAN. In a similar data, Nambiar et al. (2012) tested different concentrations of benzylaminopurine (BAP) in the induction of Dendrobium Angel White inflorescences, and found that doses of $200 \mathrm{mg} \cdot \mathrm{L}^{-1}$, $250 \mathrm{mg} \cdot \mathrm{L}^{-1}$ and $300 \mathrm{mg} \cdot \mathrm{L}^{-1}$ of BAP reduced the time of flower stem formation by 98 days compared to the control (53 days of the BAP doses vs. 151 days of the control), followed 9 days later by the usage of a $150 \mathrm{mg} \cdot \mathrm{L}^{-1}$ dose and 21 days using a $100 \mathrm{mg} \cdot \mathrm{L}^{-1}$ dose. Wu and Chang (2012) compared different concentrations of cytokinins [(Kinetin (Kin) and 2-iso-pentenyl adenine (2-iP)] vs. BA, in Phalaenopsis Sogo Yukidian 'V3' and Phalaenopsis Tai Lin Red Angel 'V31' in two stages of application ( $T_{1}$ : first day of treatment with low temperature, and $\mathrm{T}_{2}$ : when the first flower bud reached $0.2 \mathrm{~cm}$ in diameter). For both cultivars, the time to anthesis in $\mathrm{T} 1$ decreased from 3 days to 7 days; while in $T_{2}$ the opposite occurred because the DAN increased (from 3 days to 8 days above the control). On the contrary, Blanchard and 
Runkle (2008) did not obtain differences when they only sprayed BA at different times of application, in Doritaenopsis 'Alice Girl' or Phalaenopsis 'Pink Twilight'. However, they found significant differences in Doritaenopsis 'Malibu Chablis' in form of reduction in time to anthesis by 3 days compared to control (65 days vs. 68 days, respectively). Similarly, Wu and Chang (2009) found no significant differences with the application of BA $\left(50 \mathrm{mg} \cdot \mathrm{L}^{-1}, 100 \mathrm{mg} \cdot \mathrm{L}^{-1}\right.$ and $\left.150 \mathrm{mg} \cdot \mathrm{L}^{-1}\right)$ in the time to anthesis of Phalaenopsis Tai Lin Redangel 'Queen' (135.8-138.1 days compared to 139.4 days of the control). For Doritaenopsis Sogo Yukidian 'V3' they reported differences with the dose of $150 \mathrm{mg} \mathrm{L}^{-1} \mathrm{BA}$, which reached 10 days anthesis before the control (98 days vs. 108.3 days, respectively).

Another noteworthy feature of our data is the constancy shown by the dose $2.37 \mathrm{BA}+100 \mathrm{GA}_{3}$ in the three years of study, with very close periods of anthesis after having visibly induced flowering (106 days in 2017; 96 days in 2018 and 109 days in 2019 (Figure 5A-C). Contrary to our data, Blanchard and Runkle (2008) found no differences in the effect of some doses of BA and GAs and their combination in time to anthesis for Phalaenopsis Brother Apollo '072' (72-74 days average with regulators vs. 72 days with control) and Golden Treasure '470' (77-81 days with regulators vs. 78 days with control). From our data, there was observed a relationship between the doses used. Lower doses of both BA and $\mathrm{GA}_{3}$ and the combination of these (9.5, 400 and $2.37+100$, respectively) have an immediate effect by reducing DAN, that is, in 2017 (Figure 5A), while higher doses of each type of PGR $(28.5,800$ and $4.75+150 \mathrm{GA}_{3}$ ) reduced the time to anthesis, as reflected in the data for 2018 (Figure 5B).

In an established culture of $L$. anceps without application of PGRs, but under environmental conditions similar to those of the current work, the floral induction has its maximum peaks in April and May, and the anthesis is prolonged until November, with sporadic anthesis in December, that is, the flowering cycle can last 7-8 months. In the present research, when preparing the plants to match the growth of vegetative shoots with floral induction under the influence of inductive treatments with PGRs, it was clearly observed that the cycle was reduced to 3 months or 4 months in 2017, that is, to half the average time, making the flowering period further attenuated. In this case, we are discussing the key peaks of flowering (70-80\%), since in general, a certain percentage $(10-15 \%)$ has anthesis before or after the specified period (data not shown).

\section{Flower life}

Table 1 and Figure 6A show that the flower life in 2017 was higher than that corresponding to 2018 and 2019 during the experimental period. While the different doses and types of PGRs used in 2017 increased the flower life (at 25 days), it stands out even more that the high dose $\left(28.5 \mathrm{mg} \cdot \mathrm{L}^{-1}\right)$ of $\mathrm{BA}$ and intermediate dose of $\mathrm{BA}+\mathrm{GA}_{3}\left(4.75 \mathrm{BA}+150 \mathrm{GA}_{3}\right)$ presented the greatest longevity of the flower (28 days), compared to 18 days of the control (Figure 6B). The normal life of the $L$. anceps flower in culture is approximately 19 days (Tejeda-Sartorius et al., 2017), such that a difference of up to 10 days is of importance for a marketing proposal. Contrary to our results, $\mathrm{Wu}$ and Chang (2009) found no significant differences with the application of different concentrations of $\mathrm{BA}\left(50 \mathrm{mg} \cdot \mathrm{L}^{-1}, 100 \mathrm{mg} \cdot \mathrm{L}^{-1}\right.$ and $\left.150 \mathrm{mg} \cdot \mathrm{L}^{-1}\right)$ in the longevity of the flower of $P$. Tai Lin Red Angel 'Queen' and $P$. Sogo Yukidian 'V3' compared to control (without BA). Wu and Chang (2012) found differences with the use of different types of cytokinins for $P$. Sogo Yukidian 'V3', and with concentration of $100 \mathrm{mg} \cdot \mathrm{L}^{-1} \mathrm{BA}$, the greatest longevity of the flower (133 days vs. 126 days of the control) was obtained. For $P$. Tai Lin Red Angel 'V31', the greatest longevity was obtained using $50 \mathrm{mg} \cdot \mathrm{L}^{-1}$ and $100 \mathrm{mg} \cdot \mathrm{L}^{-1} \mathrm{BA}$, and $100 \mathrm{mg} \cdot \mathrm{L}^{-1}$ and $150 \mathrm{mg} \cdot \mathrm{L}^{-1} 2$-iP, respectively. The participation of cytokinins in senescence delay has been demonstrated in economically important flowering plants, such as carnation (Dianthus caryophyllus), using dihydrozeatin (Van Staden and Bossè, 1989), or in rose (Rosa hybrida), using 6-BA (Wu et al., 2017).

\section{Flower development}

BA doses began with a low percentage of bloominduced plants, but generally reached $100 \%$ in 2018 and 2019, while $\mathrm{GA}_{3}$ doses and the combination of $\mathrm{GA}_{3}$ and $\mathrm{BA}$ had similar actions over the three years, including control [between $75 \%$ and $100 \%$ (Figure 2)]. Similarly to our data, Nambiar et al. (2012) indicated that the application of BAP increased the percentage of production of $D$. angel White inflorescences up to $85 \%$ with the concentration of BAP $200 \mathrm{mg} \cdot \mathrm{L}^{-1}$ vs. $20 \%$ presented by the control. Also, Matsumoto (2006) reported lower percentage of plants with visible inflorescences, with single and combined doses of BA and GA, compared to the control, for Miltoniopsis 'Eileen' and M. 'Akatsuka', except with $5 \mathrm{mM}$ dose of GA where the same percentages were achieved as the control (96 and 89\%, respectively). On the contrary, Cardoso et al. (2010), with doses $0 \mathrm{mg} \cdot \mathrm{L}^{-1}, 125 \mathrm{mg} \cdot \mathrm{L}^{-1}$, $250 \mathrm{mg} \cdot \mathrm{L}^{-1}, 500 \mathrm{mg} \cdot \mathrm{L}^{-1}$ and $1,000 \mathrm{mg} \cdot \mathrm{L}^{-1}$ of $\mathrm{GA}_{3}$ and two irrigation frequency conditions (higher and lower frequency), found that in Brassocattleya (Bc.) Marcella Koss, the concentration of $250 \mathrm{mg} \cdot \mathrm{L}^{-1} \mathrm{GA}_{3}+$ less irrigation, induced a flowering rate of $83 \%$ vs. $17 \%$ with greater irrigation. Similarly, Cardoso et al. (2012) tested the same $\mathrm{GA}_{3}$ concentrations in the vegetative and reproductive development of Phalaenopsis FSNT 'Dai-Itigo' and found that the $125 \mathrm{mg} \cdot \mathrm{L}^{-1} \mathrm{GA}_{3}$ dose generated the highest flowering rate $(50 \%)$ compared to $16.4 \%$ of the control. With our records, the highest percentage with BA, although not in 2017, but until 
2018 and 2019, indicates that with the sympodial growth of $L$. anceps, BA is likely to have stimulated a higher emission of vegetative buds, resulting in a number of floral inductions for the next flowering cycle, with some pseudobulbs in the 2017 cycle emitting up to two new pseudobulbs each in 2018 (data not shown). Thus, except for abortion cases, the intermediate and high doses of both $\mathrm{BA}$ and $\mathrm{BA}+\mathrm{GA}_{3}$ had fewer flower stems in 2017, which increased significantly in 2018 and continued to decrease in 2019 (Table 2). Latimer and Freeborn (2009) noted that some PGRs, including BA, inhibit the growth of terminal stems and encourage the growth of lateral buds, and therefore lateral branches, in herbaceous perennials. Similar to our data, $\mathrm{Wu}$ and Chang (2012) obtained differences in the number of stems per plant of Phalaenopsis orchids, with different types of cytokinins (from 1.5 stems to 2 stems) in relation to the control (1 stem). Similarly, Blanchard and Runkle (2008) with the $400 \mathrm{mg} \cdot \mathrm{L}^{-1}$ dose of BA, mainly obtained the highest number of stems, 1 stem and 3 stems more than the control, in Phalaenopsis Brother Apollo '072' and Golden Treasure '470', respectively; while the combination of $\mathrm{BA}+\mathrm{GA}$ gave similar results to control.

Mainly, intermediate and high doses of BA, as well as intermediate $\mathrm{BA}+\mathrm{GA}_{3}$, increased the size of the flower in 2017 (mainly wide), which decreased in 2018. Similarly, Nambiar et al. (2012) found greater numbers and width of flower with $200 \mathrm{mg} \cdot \mathrm{L}^{-1}$ BAP. Blanchard and Runkle (2008) also found greater flower width with BAP doses in two Phalaenopsis cultivars, while $\mathrm{Wu}$ and Chang (2009) found no differences in the flower diameter of two Phalaenopsis cultivars with different doses of BA. Cardoso et al. (2010) reported that the diameter of flowers and petals of the B.C. Marcella Koss orchid hybrid was greater, with the highest concentration of $\mathrm{GA}_{3}\left(1,000 \mathrm{mg} \cdot \mathrm{L}^{-1}\right)$. It is important to highlight the significant increase in the number of flowers in 2018 with the dose $7.12 \mathrm{BA}+200 \mathrm{GA}_{3}$ with respect to the other two cycles, a trend similar to that of the NFS in terms of the temporal effect.

There were no significant differences in FSL with respect to the types and doses of PGRs used, since it is a parameter that presents high variability, and there may be stems from $20 \mathrm{~cm}$ to $60 \mathrm{~cm}$ or more, although the average was presented between $35 \mathrm{~cm}$ and $40 \mathrm{~cm}$. It is probable that the FSL is related to the size of the pseudobulb and flower development. Sánchez-Vidaña et al. (2018) found a significant positive correlation between FSL with pseudobulb diameter and leaf length, as well as with DAN of $L$. anceps, subjected to a controlled environment. In turn, with our data, we found a positive correlation, which was highly significant, between FSL with flower number and size in the three study periods (data not shown). It is likely that the PGRs, by reducing the DAN, also reduce a greater deployment of these variables. However, controlling the height of the flower stem of our species under study is an important parameter, due to its handling in the container and the architecture of the plant, and for this reason finding a balance between this parameter and the display of a greater attractiveness of its flowers is a suggested topic of study, in which other types of PGRs may intervene. Similarly, with our data, Sakai et al. (2000) injected doses of BA and GA into pseudobulbs of Dendrobium Jaquelyn Thomas 'Uniwai Princess' and found that high concentrations of BA significantly reduced the length of the inflorescence while the addition of GA increased it. Similarly, Wu and Chang (2009) suggest that, although BA can increase flower stems in Phalaenopsis Luchia Pink '244', many stems may not have a large number of flowers.

\section{Deformations in flowering and residuality of PGRs}

In our observations, no abnormalities were detected in flowering with any of the applied treatments and in any of the evaluation periods. Contrary to our data, Sakai et al. (2000) reported that high concentrations of BA caused the development of abnormalities in the flowers of Dendrobium Jaquelyn Thomas 'Uniwai Princess', and the addition of GA reduced the percentage of abnormal flowers. Similarly, Wu and Chang (2009) reported that P. Luchia Pink ' 244 ' presented $43 \%$ of deformed flower stems with the application of $70 \mathrm{mg} \cdot \mathrm{L}^{-1}$ of BA. The authors suggest that BA may cause deformity in the flower stems of some Phalaenopsis cultivars.

Based on our data, on the one hand, MIXED was useful in analysing the temporal effect (between years) of response variables on the quality of flowering, since no differences were detected between treatments, which is a common problem in studies with the wild orchid type, where prolonged periods of flowering complicate the sensitivity of the analysis. Thus, some variables showed a positive effect in 2017 and others until 2018. In a general overview, the two-way ANOVA analysis similarly supports the data obtained with the MIXED, regarding the effect of both $\mathrm{BA}$ and $\mathrm{GA}_{3}$ on morphoflower variables, highlighting their significance in 2017 on flower life, flower size and number of flowers in 2018. In this respect, the effect of $\mathrm{GA}_{3}$ stands out, laying an important basis for its influence on L. anceps subsp. anceps flowering, which is not well defined for other species.

On the other hand, the survival curves proved to be an accurate analysis for observing the behaviour of L. anceps flowering through the three years of study, such as the reduction of DVFI and DAN, as well as the increase in DFL in 2017 with most doses, an effect that in some cases was maintained in 2018. It is likely, therefore, that there is a potential positive residual effect of PGRs in the temporal aspect, an effect that would benefit the crop in the following cycle, in relation to the emission of vegetative shoots, flower stems and number of flowers, which may suggest modifications in the frequency and dose of application. 
There is paucity in the availability of information about the seasonality of flowering of orchids, even of economically important hybrids, and study periods are often limited to one year. However, there is evidence that flowering peaks vary with the years of cultivation when treatments are used to control flowering (Hew and Yong, 2004), as previously indicated by the three-year study using Aranda Christine 130 by Hew and Lee (1989) or using L. anceps by Sánchez-Vidaña et al. (2018). It is important to record the seasonality of flowering of the species for the market demand of flowering to be met (Hew and Lee, 1989).

\section{CONCLUSIONS}

For the temporal behaviour of flowering, it is concluded that by comparison between experimental periods and treatments, the different doses of the PGRs used, that is BA and $\mathrm{GA}_{3}$, significantly reduce the days to visible floral induction, DAN and DFL, mainly in 2017, but some retained their effects in 2018 while the majority diluted their effect in 2019. In a global context, applying PGRs reduced the flowering cycle of $L$. anceps subsp. anceps by 3-4 months in 2017, compared to a normal flowering cycle without PGRs. Similarly, different doses of PGRs generated significant differences in flower quality parameters in 2017, such as flower life and size, but the increase in flower stems and number of flowers presented its best performance in 2018. However, the dose of 2.37 $\mathrm{BA}+100 \mathrm{GA}_{3}$ showed greater positive results, due to its constancy, mainly in the temporal parameters of the three periods evaluated and some morpho-floral quality characteristics. No deformities were observed in the flowers; neither was there negative residual behaviour at the blooms in the first and the two subsequent cycles after applying the PGRs.

\section{ACKNOWLEDGEMENTS}

The authors thank and appreciate the support of the Colegio de Posgraduados, Campus Montecillo, for assistance in performing this research.

\section{FUNDING}

The authors declare that no funding was procured for carrying out the research described in this article.

\section{AUTHOR CONTRIBUTIONS}

O.T.S. designed and performed the experiment, drafted, wrote and edited the manuscript. H.V.H. performed statistical analysis. L.I.T.T. performed the nutrient solutions and edited the manuscript. R.M.S.H. and J.S.E. equally contributed to the editing of the manuscript.

\section{CONFLICT OF INTEREST}

Authors declare no conflict of interest.

\section{REFERENCES}

Amasino, R. M., and Michaels, S. D. (2010). The timing of flowering. Plant Physiology, 154(2), 516-520.

Bernier, G., Havelange, A., Houssa, C., Petitjean, A., And Lejeune, P. (1993). Physiological signals that induce flowering. The Plant Cell, 5(10), 1147-1155.

Blanchard, M. G., and Runkle, E. S. (2008). Benzyladenine promotes flowering in Doritaenopsis and Phalaenopsis orchids. Journal of Plant Growth Regulation, 27(2), 141-150.

Cardoso, J. C., Ono, E. O., And Rodrigues, J. D. (2010). Gibberellic acid and water regime in the flowering induction of Brassocattleya and Cattleya hybrid orchids. Horticultura Brasileira, 28(4), 395-398.

Cardoso, J. C., Ono, E. O., And Rodrigues, J. D. (2012). Gibberellic acid in vegetative and reproductive development of Phalaenopsis orchid hybrid genus. Horticultura Brasileira, 30(1), 71-74.

Conti, L. (2017). Hormonal control of the floral transition: Can one catch them all? Developmental Biology, 430(2), 288-301.

EMONGOR, V. (2007). Gibberellic acid (GA $)$ influence on vegetative growth, nodulation and yield of cowpea (Vigna unguiculata (L.) Walp. Journal of Agronomy, 6(4), 509-517.

HA, T. M. (2014). A review of plants' flowering physiology: The control of floral induction by juvenility, temperature and photoperiod in annual and ornamental crops. Asian Journal of Agriculture and Food Sciences, 2(3), 186-195.

Hadlow, A. P., And Allan, P. (1989). Effect of paclobutrazol on vegetative growth in citrus nursery trees. South African Journal of Plant and Soil, 6(1), 50-52.

Hágsater, E., Soto-Arenas, M. A., Salazar-Chávez, G. A., JimÉnez-Machorro, R., López-Rosas, M., A., AND Dressler, R. L. (2005). Las Orquídeas de México. Instituto Chinoín, México, 304 pp.

Hew, C. S., And Clifford, P. E. (1993). Plant growth regulators and the orchid cut-flower industry. Plant Growth Regulation, 13(3), 231-239.

Hew, C. S., AND LeE, F. Y. (1989). Control of flowering by floral bud removal in $\times$ Aranda Christine under tropical field conditions. Journal of the Japanese Society for Horticultural Science, 58(3), 691-695.

Hew, C. S., And Yong, J. W. (2004). Physiology of tropical orchids in relation to the industry. Singapore: The World Scientific Publishing Company.

Kishore, K., Singh, H. S., and Kurian, R. M. (2015). Paclobutrazol use in perennial fruit crops and its residual effects: A review. Indian Journal of Agricultural Sciences, 85(7), 863-872.

Kleinbaum, D. G., and Klein, M. (2005). Competing risks survival analysis. In D. G. Kleinbaum, and M. Klein (Eds), Survival analysis: A self-learning text. Statistics for biology and health (pp. 391-461). New York, NY, USA: Springer.

KozŁowska, M., Rybus-Zając, M., Stachowiak, J., AND JANOwSKA, B. (2007). Changes in carbohydrate 
contents of Zantedeschia leaves under gibberellinstimulated flowering. Acta Physiologiae Plantarum, 29(1), 27-32.

Latimer, J., AND Freeborn, J. (2009). New uses of PGRS in ornamentals: Configure (6-BA) increases branching of herbaceous perennials. Proceedings Plant Growth Regulation Society of America, 36, 88-93.

Levy, Y. Y., and Dean, C. (1998). The transition to flowering. The Plant Cell, 10(12), 1973-1989.

Matsumoto, T. K. (2006). Gibberellic acid and benzyladenine promote early flowering and vegetative growth of Miltoniopsis orchid hybrids. HortScience, 41(1), 131-135.

Nambiar, N., Siang, T. C., and Mahmood, M. (2012). Effect of 6-Benzylaminopurine on flowering of a Dendrobium orchid. Australian Journal of Crop Science, 6(2), 225-231.

Nickell, L. G. (1994). Plant growth regulators in agriculture and horticulture. In P. A. Hedin (Ed.), Bioregulators for crop protection and pest control. A.C.S. Symposium Series. American Chemical Society. Washington, DC.

Phengrhachanh, B., Naphrom, D., Bundithya, W., and Potapohn, N. (2012). Effects of day-length and gibberellic acid $\left(\mathrm{GA}_{3}\right)$ on flowering and endogenous hormone levels in Rhynchostylis gigantea (Lindl.) Ridl. Journal of Agricultural Science, 4(4), 217-222.

RADEMACHER, W.(2018). Chemical regulators of gibberellin status and their application in plant production. Annual Plant Reviews Online, 49, 359-403.

Richards, D. E., King, K. E., Ait-Ali, T., And Harberd, N. P. (2001). How gibberellin regulates plant growth and development: A molecular genetic analysis of gibberellin signaling. Annual Review of Plant Biology, 52(1), 67-88.

SajJad, Y., Jaskani, M. J., Asif, M., and Qasim, M. (2017). Application of plant growth regulators in ornamental plants: A review. Pakistan Journal of Agricultural Sciences, 54(2), 327-333.

Sakai, W. S., Adams, C., And Braun, G. (2000). Pseudobulb injected growth regulators as aids for year around production of Hawaiian Dendrobium orchid cutflowers. Acta Horticulturae, 541, 215-220.
SÁnchez-Vidaña, M. R., TeJedA-SARtorius, O., Hernández-Anguiano, A. M., Trejo-Téllez, L., Soto-Hernández, R. M., And Gaytán-Acuña, E. A. (2018). Ambiente y antecedentes de floración en el crecimiento, inducción y desarrollo floral de Laelia anceps subesp. anceps (Orchidaceae). Agrociencia, 52(1), 35-54.

Tejeda-Sartorius, O., Téllez-Velasco, M. A. A., And Trejo-Téllez, L. I. (2017). Características ornamentales de orquídeas silvestres y su propagación con fines comerciales. alternativa de aprovechamiento sustentable ex situ. Agroproductividad, 10(6), 37-45.

Van Staden, J., and Bosse, C. A. (1989). Cytokinins in cut carnation flowers. VI. The transport and metabolism of zeatin and dihydrozeatin. Journal of Plant Physiology, 135(2), 160-163.

Wang, H. M., Tong, C. G., AND JANG, S. (2017). Current progress in orchid flowering/flower development research. Plant Signaling \& Behavior, 12(5), e1322245, doi: 10.1080/15592324.2017.1322245.

Wang, S. L., Viswanath, K. K., Tong, C. G., An, H. R., JANG, S., ANd ChEn, F. C. (2019). Floral induction and flower development of orchids. Frontiers in Plant Science, 10, 1258, doi: 10.3389/fpls.2019.01258.

Wu, L., Ma, N., Jia, Y., Zhang, Y., FenG, M., Jiang, C. Z., Ma, C., AND GaO, J.(2017). An ethylene-induced regulatory module delays flower senescence by regulating cytokinin content. Plant Physiology, 173(1), 853-862.

Wu, P. H., And Chang, D. C. (2009). The use of N-6benzyladenine to regulate flowering of Phalaenopsis orchids. HortTechnology, 19(1), 200-203.

Wu, P. H., AND Chang, D. C. (2012). Cytokinin treatment and flower quality in Phalaenopsis orchids: Comparing N-6-benzyladenine, kinetin and 2-isopentenyl adenine. African Journal of Biotechnology, 11(7), 1592-1596.

ZaŁuski, D., Mielniczuk, J., Bronowicka-Mielniczuk, U., Stolarski, M. J., Krzyżaniak, M., SzczuKowski, S., And Tworkowski, J. (2018). Survival analysis of plants grown in long-term field experiments. Agronomy Journal, 110(5), 1791-1798.

Received: December 22, 2020; accepted: March 8, 2021 